\title{
A Brief Literature Review on Structure, Conduct and Performance Paradigm: Critical Analysis for the Indian Industry
}

\section{Khushboo}

\author{
Masters in Economics Jawahar Lal Nehru University, New Delhi-110067.
}

*Corresponding Author Email: yadav.khushboo29@gmail.com

Abstract: The paper critically reviews the famous study of the SCP paradigm in the Indian context. It also tries to compare and contrast both paper by Athreye \& Sandeep Kapur[4] and Bhandari [5] concerning the research question, data, and model used, econometric technique, and finally, results.

Keywords: Performance Paradigm, Indian Industry, Critical Analysis.

\section{Introduction}

Bain pioneered [1] the famous SCP paradigm, conducted an intra-industry study for the US manufacturing industry. He found out that the market structure, such as the number of sellers, product differentiation, cost structure, determines market conduct, which is behavioral rules chosen by market agents like sellers, buyers, potential entrants.

In turn, market conduct affects market performance, often measured in terms of efficiency, price-cost margin, profits, etc. SCP theory states that highly concentrated firms with an additional barrier to entry have an additional and separate effect on firms' profitability due to their high market power. Another school of thought Chicago school's hypothesis has a polar opposite view of the SCP paradigm, pioneered by Demsetz [2].

They believe that highly concentrated firms may enjoy higher profits not because they can charge higher prices but because they gain differential efficiency by capturing large market shares. According to the Chicago school's hypothesis, the market concentration may be positively related to profitability not due to market power but because the firms might earn high economic rent due to their efficiency to minimize their costs.
Later many studies have worked on the SCP paradigm in the context of the US industry. Delorme et al [3] uses a simultaneous framework model and found out that there exists no reverse causality between market structure and profitability. The main finding is that profitability depends on market concentration. However, the reverse need not be true because the market structure may be affected by market conduct variables, which affects firms' profitability.

Most studies have been conducted in a developed country like the UK, USA, Canada, because the SCP paradigm is essentially a developed market phenomenon. In developed countries like the US, there were no strict policies and regulatory frameworks for Industries to support domestic firms. The change in the market structure can only be contributed to see the market performance, which can be measured as the firms' profitability.

Developed economies have smooth and liberal government industrial policies and regulations that would leave little scope for ambiguity in analyzing whether the government policies have determined the market structure or due to regular competition policy [4]. Studying the SCP paradigm in emerging economies is entirely 
different because the industries of these economies often come under the transitional phase from regulation to deregulation phase. For example, in developing countries like Indian, industries were highly regulated in the 1960 and 1970s.

During the pre-liberalization era, industries have strict trade restrictions such as restrictions on foreign firms' entry, licensing, and permits. From 1985 and onwards, there was some relief given to Indian industries regarding liberal policies and free foreign trade regulation. In the deregulation phase, the Indian industry has witnessed many changes like abolishing licensing and royalty payments for many firms and exposure to foreign competition.

Studying the SCP paradigm for emerging economies is equally relevant in the context of policymaking. It helps in policy suggestions for the state or government. This policy implication is beneficial to suggest which industrial policy framework would better work - either industry-specific or for the whole industry. Such inter-industry studies would help the economy come out of the periods of stagnant growth of industries, which may arise due to technological stagnation or lack of competition.

Since industries of developing economies are its transitional phase, studies were conducted to ask the relevant question of whether the deregulation government policy increases or decreases the market concentration, which could impact price, technology, and welfare later. Suma Athreye \& Sandeep Kapur [4] study the Indian manufacturing sector's SCP paradigm for both the pre-liberalization and postliberalization phase of Indian economies.

The paper unravels the relevant question that if the Indian industry's deregulation impacts industrial concentration. It asks if there is any impact on the market concentration due to strict and restrictive government policies during the preliberalization era or has market concentration increased or decreased during the post-liberalization phase. The paper is looking for any evidence to support the famous SCP paradigm in the context of emerging economies, especially in the postliberalization era. It considers the various determinants of market concentration like market size, R\&D, advertisement expenditure, technological intensity. It tries to assess if the determinants significantly impact market concentration in the Indian industry's post-liberalization era. Contrastingly, the other study conducted by Bhandari [5] also applies the Indian manufacturing sector's SCP paradigm.

The main research question is that during the deregulated phase of Indian economies, there is any reverse causality between market structure, particularly market concentration and profitability of firms in Indian industries. The focus of the study was solely on the liberalized phase of the Indian economy.

The primary purpose of liberalization was to make Indian economies a more free, liberal, and developed one. Thus, the postderegulation phase more and less resembles developed countries' economies where government industrial policy was less strict, and foreign firms were allowed to enter so that the SCP paradigm was validated in the post-deregulation phase. Suma Athreye \& Sandeep Kapur [4] use long data series of medium and large, non-government, public limited firms from 1970 to 1999, obtained a balance sheet of these firms from a data source, RB1.

It covers all such industries operating both in the pre- and post-deregulation phases of the Indian industry. There are several limitations in the data set. The data excludes small-scale firms, privately-held firms, and public sector firms. It suffers from overestimation problem while measuring the concentration in those sectors where many small-scale firms already exist and contribute larger shares of outputs. The paper uses unbalanced panel data as the number of industries fluctuates from incumbent firms' new entrants and exit. It is hard to capture reporting variations from the firms' new entry and exit during the Indian industries' transition phase.

In contrast, Bhandari [5] uses company level annual data of thirty-seven industries data for 13 years from 1993 to 2005. This period considered here is the post-deregulation phase. The paper uses balanced panel data set with the total number of observations -48 
for industry-level study. The source of data is the Prowess database by the Centre for Monitoring Indian Economy (CMIE). The paper by Suma Athreye \& Sandeep Kapur [4] adopted a more flexible theoretical approach to do extensive empirical analysis. It tries builds a hypothesis based on previous empirical works of few studies by and identifies the significant determinants of industrial concentration such as the market size relative to the technologically-given setup costs, advertising intensity, and technology intensity.

The hypothesis states that these determinants have significant explanatory powers in explaining the concentration level during the post-liberalization phase. It is built on the fundamental premise that these determinants do not matter during the preliberalization phase due to the tight regulatory framework and industrial policies. However, during the post-liberalization phase, the Indian economy has become more competitive, which gives scope for advertising and expenditure on technology. They play a more substantial role in determining the concentration level.

It then tries to test the hypothesis with an econometrical model. In contrast, Bhandari [5] tries to build his theoretical model by extending the previous model by using conjectural behaviors (Dixit \& Stern [6]. The paper extends the theoretical model to depict that profit to revenue ratio depends not only on Concentration (HHI) and collusive parameter but also on the degree of product differentiation. This extended model is relevant to hypothesize that market profitability depends on both market structure and conduct parameter.

He does not rely on past literature; instead, he builds his theoretical model by extending past models. Summarizing the above argument, Bhandari [5] adopts theory building approach in his study while Suma Athreye \& Sandeep Kapur [4] approach theory testing. On comparing both papers with respect to the econometric model. In the paper by Suma Athreye \& Sandeep Kapur [4] the model tries to study the determinants of industrial concentration levels.

The major dependent variable is concentration variables (Four-firm concentration ratio, denoted CR4 and HHI), and explanatory variables such as the size of the market for any industry relative to set up cost, marketing intensity, and technological intensity, whereas in Bhandari (2010) paper's econometric model tries to assess the effect of market structure and conduct variables on profitability of firms. The major dependent variable is profitability variable-rate of return (ROR) and profit after tax, profit before tax, profit before depreciation and tax, profit before depreciation, interest, and tax.

The explanatory variables are concentrationvariables CR4 and HHI -sum of the squares of the shares of all firms, entry barriers variables such as advertising intensity, minimum efficient scale, R\&D intensity, value added to sales ratio -this ratio reflects the degree of vertical integration, CapitalSales Ratio (Kas): market structure variables.

The paper Suma Athreye \& Sandeep Kapur [4] has chosen the year 1985 as the demarcation point between the two phases based on the empirical work of DeLong's [3], who studies Indian growth and found there is a structural break in per capita GDP occurred in the year 1985. In contrast to Bhandari [5], this paper has not conducted any Hausman test to select a fixed-effect model or random effect.

Finally, the paper by Suma Athreye \& Sandeep Kapur [4] has shown that the determinants of concentration level and market intensity are statistically significant and negatively related to the concentration variables in the post-liberalization period. Technological intensity is not found to be significant in either period of pre and postderegulation phase. The dynamic adjustment model also signifies the role of the sunk cost variable. The disaggregated approach helps them find out that due to concentration levels fell in some sectors, and it has risen in other sectors.

The paper talks about the policy implication by showing its results. It suggests that emerging economies state should adopt a sector-specific approach to industrial policy. The result has shown that the implication of deregulation policy on industrial concentration differs across the sector. The result by Bhandari [5] confirms that entry 
barrier variables like advertisement intensity, minimum efficient scale, R\&D intensity, and degree of vertical integration indeed have affected profitability significantly.

It says that market structure variables like industry concentration have a significant positive effect on the Indian industry's profitability in the Indian economy's postderegulation phase. Both results suggest that market conduct variable like entry barriers has a major impact on market structure variable, which affects the firm's market performance. SCP paradigm is valid in the Indian manufacturing sector as well, given that we only consider the post-liberalization era.

There is a significant impact on industries' profitability due to market structure via market conduct variables like entry barriers and product differentiation, such as vertical integration. Bhandari [5] finds out that advertisement intensity is found to act as both an entry barrier and product differentiation on differences in profitability across Indian industries.

The result supports the stylized fact given by Schmalansee [7], advertising intensity is positively related to industry profitability in the context of Us manufacturing industries. The positive relation is due to advertisement intensity entry barriers as well as product differentiation. According to the stylized fact of Schmalansee [7], there exists a positive relationship between the profitability and concentration of industry leaders in US manufacturing industries.

However, results may not necessarily hold for the small firms owning smaller market shares. The evidence could be found in the Indian manufacturing sector and postderegulation face many new manufacturing firms entered into the market, which raises doubt for robustness in the result if it still holds for industry followers in the Indian context.

\section{Limitations}

In the paper by Suma Athreye \& Sandeep Kapur, there is a problem in choosing a variable. One of the determinants of industrial concentration level, size-setup ratio - the median value of net fixed assets is a reasonable proxy of concentration itself. Its significance as an explanatory variable is doubtful in the cross-sectional analysis. It can also bias the econometric model of panel data analysis [8]. Bhandari's [5] paper also has several limitations. Firstly, it is challenging to study the level of concentration when the Indian industry was in the policy change phase. Despite liberalized government policies, we cannot deny that institutional constraints on entry and exit still determine the market structure. Secondly, deregulated industrial policies and framework has an ambiguous impact on the direction of changes in concentration.

Deregulation may cause concentration to fall in sectors where regulation had induced it to be artificially high and to rise in sectors where it had been artificially low. This paper could not relate changing concentration levels in the Indian industry to policy changes. They can only study how policy changes aff ected the market size, setup costs, technology, and marketing intensities in this industry.

Both the paper has analyzed the SCP paradigm in the Indian manufacturing industry and supports the evidence of firms' profitability is due to market power. There is another stylized fact Schmalansee [7], which states that in a sample of US firms and business units, market shares are strongly correlated to the profits. However, within a particular manufacturing sector where a small number of sellers, market shares are not generally correlated with profitability.

For example, Collins \& Preston [9] finds out that the difference between large and small firms are not related to a subsequent change in concentration, as Demsetz would suggest. Similarly, many past studies have been done during the pre-liberalization phase. Regulatory policies have made the capital market imperfect. Sub-optimal contractual arrangements cause higher market transaction costs, which are the primary source of market power to large firms and entry barriers to small ones [10].

It raises a debatable argument that still holds in the context of the Indian industry. Studies have left room for future research scope to test the validity of the Chicago Schools Hypothesis. It can be interesting to 
conduct an intra-industry study in the Indian economy's context for the post-deregulation period to see whether the industries are gaining profits due to market power or efficiency in their costs advanced method of cost estimation.

\section{Conclusion}

Finally, the review concludes that Bhandari's [5] paper is more rigorous for econometric techniques. It uses standard regression techniques. The paper has used the Hausman test to select an appropriate regression equation model from two alternative panel data models: the fixed effect (FE) model and the random effect (RE) model.

This test's basic idea is to test whether the unobserved industry-specific heterogeneity is correlated with regressors in the models. If there is a correlation between regressors and the unobserved industry-specific heterogeneity, FE is best suited. Otherwise, $\mathrm{RE}$ is more efficient. Bivariate analysis

\section{References}

1. Bain J (1951) Relation of Profit Rate to Industry Concentration: American Manufacturing, 1936-1940. The Quarterly Journal Of Economics, 65(3):293. doi: $10.2307 / 1882217$

2. Demsetz H (1973) Industry Structure, Market Rivalry, and Public Policy. The Journal Of Law And Economics, 16(1):1-9. doi: $10.1086 / 466752$

3. De Lorme C, Klein P, Kamerschen D, Voeks L (2003) Structure, conduct and performance: a simultaneous equations approach. Applied Economics, 35(1):13-20. doi: $10.1080 / 00036840210147149$

4. Athreye S, Kapur S (2006) Industrial concentration in a liberalising economy: A study of Indian manufacturing. The Journal Of Development Studies, 42(6):981-999. doi: 10.1080/00220380600774764

5. Anup Kumar Bhandari (2010) Concentration, Entry barriers and Profitability in the Indian Industries: An Empirical Analysis, Journal of Quantitative Economics, 8 (2). between a pair of variables is done where each explanatory variable is included in the model in a step by step fashion. The result is then compared in each model to check if R2 improves by adding more explanatory variables at each step at a 10 percent level of significance. It estimates two-way error component variation to remove the problem of cross-sectional heteroscedasticity and timewise autocorrelation [11], which makes the study more rigorous.

The latest study by Kumar Pradeep [12-13] studies for the US banking industry tries to analyze if the cost efficiency is driving the profitability. He uses the advanced moment inequality method to estimate the cost to measure its effect on firms' profitability. The literature can be extended using the latest data and analyzing the Indian manufacturing sector's SCP paradigm. We can look for evidence to support the Chicago school hypothesis to check if the market is earning profitability due to market power or costefficiency.

6. Dixit A, Stern N (1982) Oligopoly and welfare. European Economic Review, 19(1):123-143. doi: 10.1016/00142921(82)90008-3

7. Schmalensee R (1989) Intra-Industry Profitability Differences in US Manufacturing 1953-1983. The Journal Of Industrial Economics, 37(4):337. doi: $10.2307 / 2098372$

8. Davies L (1991) A stochastic model for interlaboratory tests. Computational Statistics \& Data Analysis, 12(2):201-209.

9. M Collins, N Preston L (1969) Concentration and Price-Cost Margins in Manufacturing Industries. Economica, 36(142):224. doi: $10.2307 / 2551922$.

10. Patibandla M (1998) Structure, organizational behavior, and technical efficiency: The case of an Indian industry. Journal Of Economic Behavior \& Organization, 34(3):419-434. doi: 1016/s0167-2681(97)00083-8

11. Parks J (1967) Automatic recognition of low-quality printed characters using analogue techniques. Radio and Electronic 
Engineer, 34(2):67.

10.1049/ree.1967.0067

12. Kumar P (2018) Market power and cost efficiencies in banking. International Journal of Industrial Organization, 57:175223. doi: 13. Schoeffler S, Bain J (1957) Barriers to New Competition. Journal

of Marketing, 21(4)488. doi: 10.2307/1247273 